Arch. Dis. Childh., 1965, 40, 637.

\title{
OBSERVATIONS ON BLOOD PRESSURE IN NEWBORN INFANTS
}

\author{
BY \\ J. M. GUPTA and J. W. SCOPES \\ From the Nuffield Neonatal Research Unit, Institute of Child Health, Hammersmith Hospital, Lcr.don W.12
}

(RECEIVED FOR PUBLICATION MARCH 29, 1965)

The measurement and recording of blood pressure in newborn babies is fraught with technical difficulties. Direct measurement from an artery is certainly the most accurate method (de Bono, 1963) but has obvious limitations, particularly if repeated observations over a period of hours or days are required. It involves entering an artery, strict asepsis, and expensive equipment for recording. Repeated measurements by indirect means are at best time consuming and tiring for both baby and observer (Ashworth, Neligan, and Rogers, 1959), and at worst upsetting to the baby and, therefore, inaccurate and valueless. Many ingenious methods of measuring blood pressure indirectly have been devised, but all of them have their limitations. The subject was reviewed by Young (1961) who discussed the various means employed and reviewed the findings.

In this unit we have recently had special opportunities to measure blood pressure. First, an apparatus has been devised that automatically records a baby's blood pressure at 2-minute intervals. This has made possible an assessment of blood pressure changes over the course of hours and days, and the patterns of blood pressure variations, including any circadian or shorter rhythms. Secondly, babies who require frequent sampling of blood for clinical reasons (for example, premature babies with the respiratory distress syndrome) have an umbilical arterial catheter inserted soon after birth, and we have taken advantage of the opportunity to make direct measurements of blood pressure in a variety of babies with different clinical conditions, and of varying size and gestation.

\section{Automatic Recorder}

With this instrument, which is an adaptation of that described by Ball, Pallett, and Shillingford (1961) for recording digital blood pressure in adults, blood pressure is recorded indirectly from an arm or leg, and all the technical hazards of such indirect recording apply. The apparatus consists of two cuffs placed on the baby's arm (or leg), a sensing device for detecting pulsations, a pump which operates automatically at 2-minute intervals, and a mechanical recorder (a diagram of the mechanical connexions is shown in Fig. 1). At 2-minute intervals the proximal occluding cuff is blown up to $150 \mathrm{~mm} . \mathrm{Hg}$ over the course of 10 seconds and at the same time the distal sensing cuff is blown up to a pressure $10 \mathrm{~mm} . \mathrm{Hg}$ below that of the occluding cuff to render it turgid. The pressures fall in parallel over the next 45 seconds by a controlled leak to air. As soon as pulsation is detected in the distal cuff, the mechanical recorder whose needle is moving on the surface of a drum begins to write. There is then an interval of about 1 minute when the pressure of both cuffs is nil to rest the arm before the cycle is repeated.

The cuffs used are standard $2.5 \mathrm{~cm} . \times 15 \mathrm{~cm}$. size ('Neligan' cuffs, supplied by Charles Thackray Ltd.). Pulsation is detected by the method of Pallett (1962), which depends on the small movement of air caused by pulsation being led through a capillary tube and playing on a heated thermistor bead. The bead is cooled sufficiently by this tiny puff of wind to alter its electrical resistance and give a signal. To reduce artefacts caused by the child moving his arm, it is arranged that the signal must be synchronous with pulsation taken in the same way from the occluding cuff before the recorder will write. The needle on the recorder moves vertically over the drum with each cycle and the drum rotates slowly over a 12-hour period. One is thus presented with a series of dotted lines, the vertical length of which is proportionate to the pressure being recorded. Calibration is achieved simply by having a mercury manometer attached on the side arm of the occluding cuff pressure lead.

The pressures recorded by this apparatus read somewhat lower than simultaneous measurement by auscultation or the xylol bead technique, and somewhat higher than those recorded by the 'flush' 


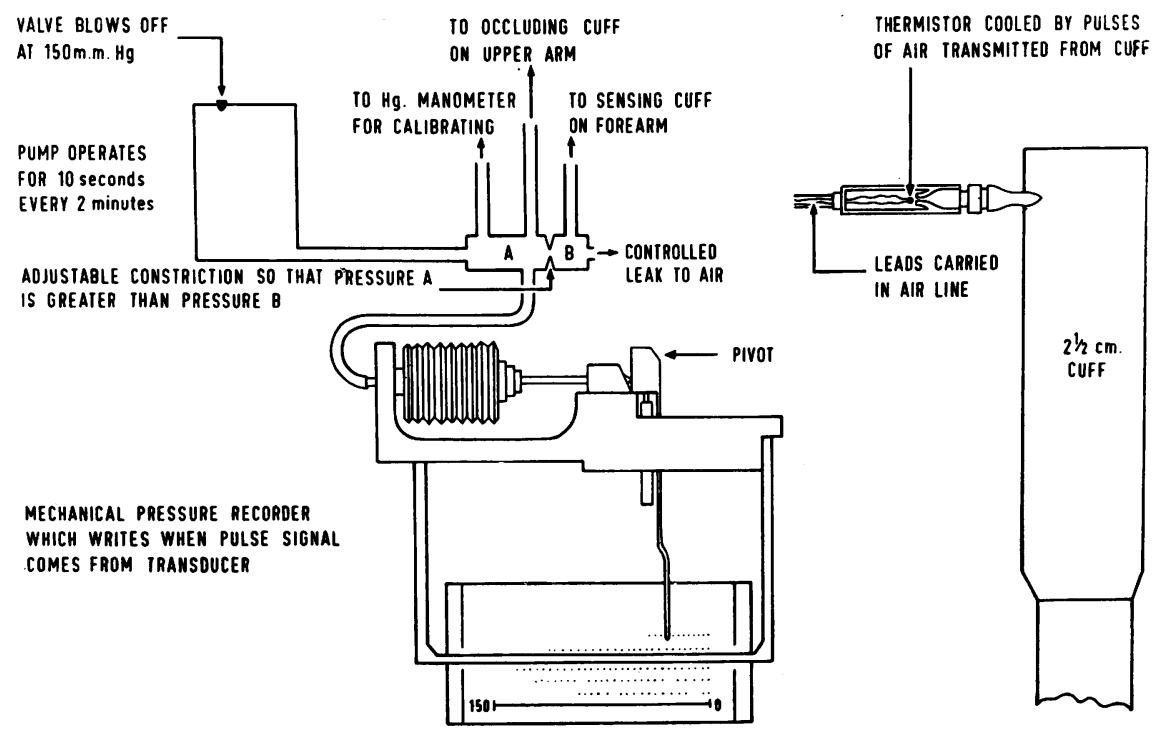

FIG. 1.-The automatic recorder-diagram of mechanical parts.

technique. On six occasions the readings have been compared with direct arterial pressure from an umbilical artery, when the pressure recorded was within $5 \mathrm{~mm}$. of the mean blood pressure. Although measurement of absolute levels of blood pressure are not entirely satisfactory by this method, variations are well shown and represent the main concern of this part of the paper.

In full-term infants, the child's arm is unaffected by up to $\mathbf{1 2}$ hours of recording. In premature infants the hand sometimes begins to become oedematous after about 6 hours' recording, but this may be obviated by changing from one arm to another at intervals of 4 to 6 hours.

The results of the use of this instrument on just over 50 babies in the Neonatal Ward are presented here. These babies varied in weight from 1,200 to $3,600 \mathrm{~g}$. and from 29 to 41 weeks' gestation. The interest in using this instrument lies not in the absolute levels of blood pressure obtained (which were in general agreement with levels obtained by other indirect techniques (Young, 1961)) but in the variations occurring during the day.

Fig. 2 shows a typical example of a tracing from a 3-day-old baby. The blood pressure of a baby fluctuates widely with the innumerable stimuli to which he is subject. Many minor procedures are accompanied by a large rise in blood pressure, and apart from periods when the baby is very quiet, a single blood pressure recording can be

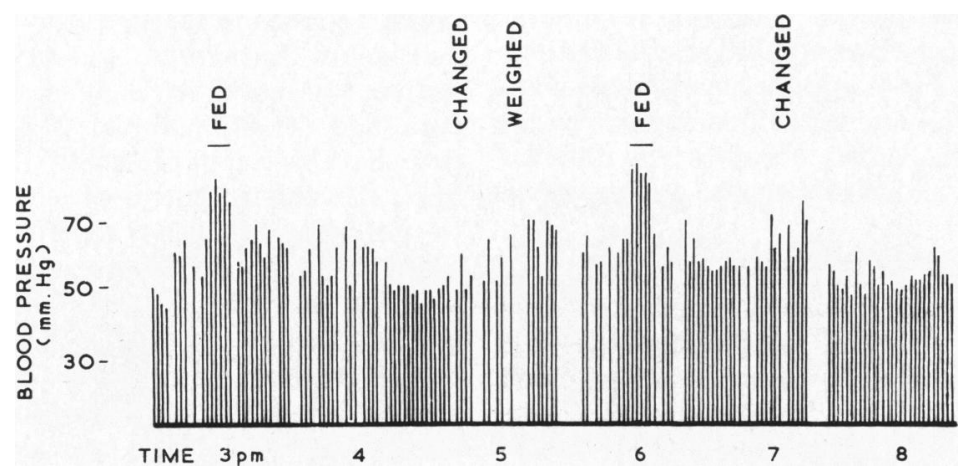

FIG. 2.-Record of blood pressure over a 6-hour period in a b 1 by of $2,400 \mathrm{~g}$. (see text). 


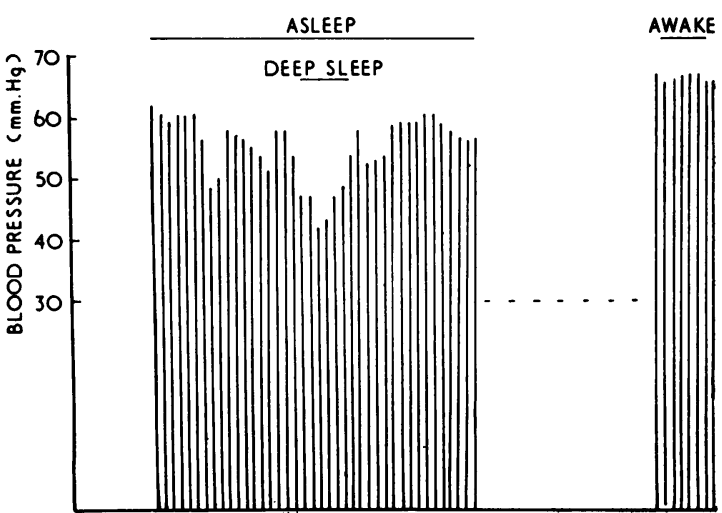

FIG. 3.-Record of blood pressure illustrating the fall that occurs in deep sleep. Each vertical line denotes an interval of two minutes. The dotted line indicates a broken time scale.

far from representative of his 'basal' level. Normal babies do not stay in the Neonatal Ward for longer than a week or ten days, and in this time no circadian rhythm appeared. Premature babies were tested up to the age of 6 weeks, and under the somewhat artificial conditions of such a baby in hospital no circadian rhythm was seen. A series of changes related to feeding and sleeping were seen in almost all babies and a typical example is represented by Fig. 2. The blood pressure rises impressively by up to $20 \mathrm{~mm}$. $\mathrm{Hg}$ during the feed, and settles after the feed to a 'resting' level. It tends to remain at this level for $\frac{1}{2}$ to 1 hour and then, as the child becomes deeply asleep, the level falls profoundly (Figs. 3 and 6). This fall appears to be related to the deep sleep phase described by Goldie (1964), for in it eye movements are absent, respiration is quite regular, and there is no movement apart from an occasional jerk. As the child emerges from this deep phase of sleep the blood pressure again rises to approximately the resting level. With the next feed, there is again a large rise in blood pressure. Almost any interference tends to cause a temporary rise in blood pressure.

The rise in blood pressure during a feed is the most striking feature of these variations. It was quite consistent and frequently as large as $20 \mathrm{~mm}$. $\mathrm{Hg}$. Some of the factors that might be responsible for this were investigated individually. Fig. 4 shows that when a child is allowed to suck a teat flavoured with $5 \%$ dextrose there is a substantial rise in blood pressure. This rise did not occur on insertion of the teat into the mouth unless the child sucked. The changes in blood pressure in Fig. 4 were noticed to be directly related to the vigour of the baby's sucking. In Fig. 4 (right hand section), there was no sucking for two minutes after insertion of the teat when vigorous sucking was observed. This sucking be-

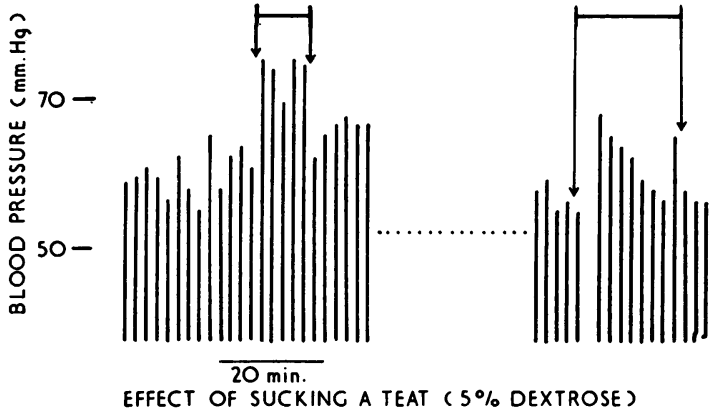

Fig. 4.-Effect on blood pressure of sucking a teat flavoured with $5 \%$ dextrose (see text).

came progressively less until just before the teat was removed. A feed through a gastrostomy tube caused no rise in blood pressure in one infant. When a child is being fed by gavage, the tube being inserted through the mouth, there is a rise in blood pressure, not as well sustained as in an ordinary feed (see Fig. 5), and, in general, the rise occurs when the child is sucking on the tube through his mouth.

Other factors that may add to the rise in blood pressure during a feed include sitting the baby up and general arousal. Tilting to a head-up position causes a rise in blood pressure, and feeding a baby lying in his incubator causes a smaller rise in blood pressure than when he sits up for the feed. 'Arousal' is difficult to define, but a baby with his eyes open and a small amount of physical activity has a higher blood pressure than when he is completely quiet (see Figs. 2, 3, and 6).

The effect of mild cooling was examined, but it was difficult to separate the effect of the cooling from the slight arousal which is almost always produced.

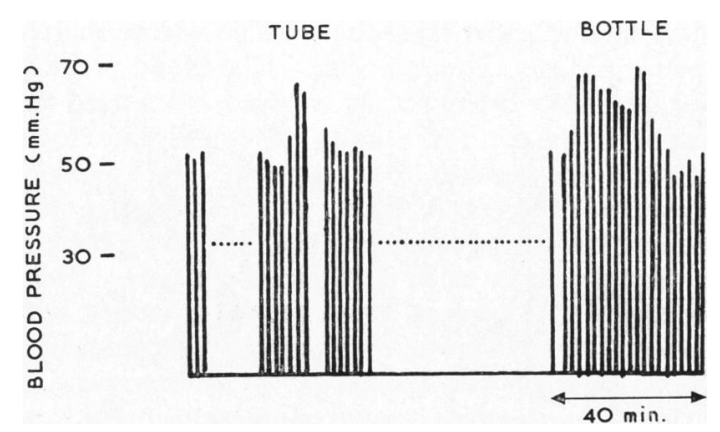

Fig. 5.-Effect on blood pressure of feeding by gavage and by bottle. The dotted line indicates a broken time-scale. 


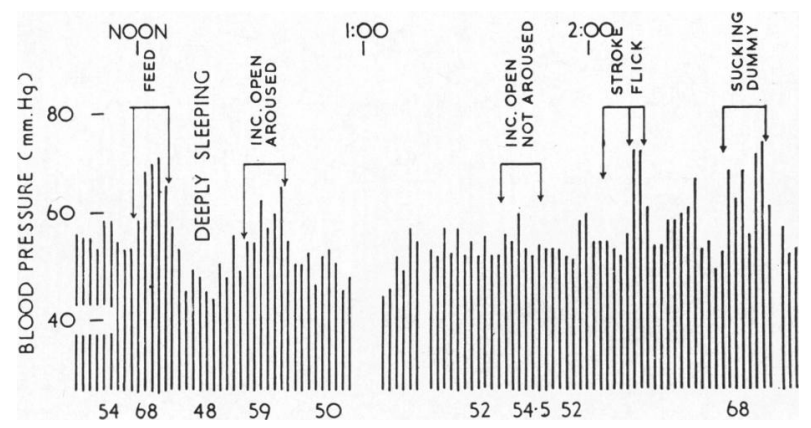

FIG. 6.-The blood pressure of a 1-week-old baby weighing $1,650 \mathrm{~g}$. and its variation with various stimuli. The figures under the tracing refer to the average blood pressure over the ten-minute period concerned.

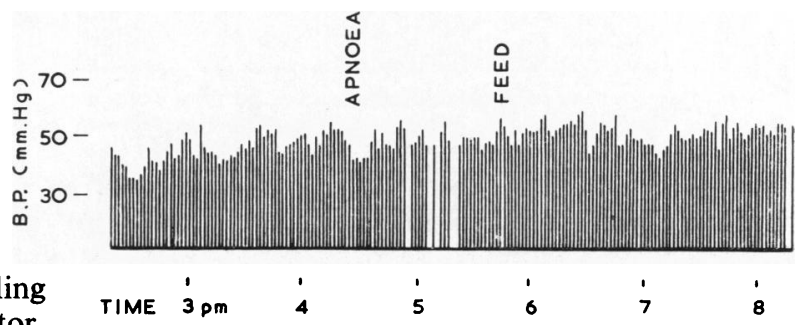

Fig. 6 shows an example of such a test where cooling was achieved crudely by opening the incubator. (This obviously involves stimuli other than that of cooling.) During the period of cooling when there was no clinical arousal the blood pressure was slightly, but not statistically significantly, higher.

Neligan and Smith (1960) have reported a small steady rise in blood pressure in babies with respiratory distress after the first few hours of life. This was seen on a number of occasions and is illustrated by the tracing in Fig. 7 in a $1,880 \mathrm{~g}$. baby, aged 12 hours and in Fig. 10. The fall in blood pressure at 4.30 p.m. in Fig. 7 was associated with a period of apnoea. A tube feed was given at 5.45 p.m. without any obvious change in blood pressure. This baby also showed a curious cycling of blood pressure approximately every $\frac{1}{4}$ to $\frac{1}{2}$ hour for which no obvious explanation was apparent.

\section{Direct Blood Pressure from the Umbilical Artery}

The umbilical arterial catheter was connected to an Electro-Scholander transducer which was calibrated against a mercury manometer. The blood pressure was recorded on paper at a speed of $5 \mathrm{~mm}$. per second in the form of a pulse wave, and thus it was possible to measure both systolic and diastolic pressures with each heart beat. Damping was reduced by making sure that there were no air bubbles in the transducer or in the arterial catheter. Mean pressures (i.e. average pressure in the artery with respect to time) were recorded directly, by abolishing the pulse wave with damping. Whenever possible an electrocardiogram was taken simultaneously. At first the recording was done with the baby flat in the incubator. This was followed by the baby in the

sitting position for two minutes. The baby was then laid flat for two minutes. The blood pressure was then recorded for two minutes with the baby's head down at an inclination of $30^{\circ}$. If the baby cried during any of these observations the whole procedure was repeated. In a number of cases where it was not possible to keep the infant quiet with the head up or down the procedure was abandoned. Recordings were also done while the infant was being fed either by the bottle or the tube. In all these measurements the transducer was kept at the level of the infant's heart. All the recordings were done before the age of 24 hours and in most of the cases it was between 6 to 18 hours after birth.

A total of 43 infants was studied (Table 1). 15 of them weighed more than $2,500 \mathrm{~g}$. Of these 15 infants, 6 were of diabetic mothers, 3 had respiratory distress syndrome, 2 had severe perinatal anoxia with convulsions, and the other 4 had haemolytic disease of the newborn. The blood pressure in the latter 4 was recorded during an exchange transfusion (done via the umbilical vein). The babies of diabetic mothers were not hypoglycaemic at the time of recording the blood pressure. The remaining 28 infants weighed less than $2,500 \mathrm{~g}$. These are divided into those that weighed 1,501-2,500 g. and those that weighed less than $1,500 \mathrm{~g}$. These two groups were further subdivided into infants small for their gestation (i.e. arbitrarily defined as those 
weighing $750 \mathrm{~g}$. or more below the mean for their gestation) and infants within the normal weight range. Some of the infants referred to as normal in both Tables had blood glucose concentrations of less than $20 \mathrm{mg}$. $/ 100 \mathrm{ml}$. at some time during the neonatal period though not at the time when the blood pressure was recorded.

Results are shown in Table 2.

Infants of Birth Weight More than 2,500 g. Infants of diabetic mothers had an average blood pressure of $71 / 48 \mathrm{~mm}$. $\mathrm{Hg}$ when lying flat, which rose to $80 / 57 \mathrm{~mm}$. Hg when sitting up and fell to $65 / 44 \mathrm{~mm}$. $\mathrm{Hg}$ with head down. The mean pressure when flat was $58 \mathrm{~mm}$. Hg. During feeding the blood pressure rose to $78 / 56 \mathrm{~mm}$. $\mathrm{Hg}$ and during crying it rose to $92 / 53 \mathrm{~mm}$. Hg.

The average blood pressure $(63 / 45 \mathrm{~mm} . \mathrm{Hg})$ in the infants with respiratory distress syndrome was less than the above-mentioned infants. Again there was $a$ rise in blood pressure with raising the head (68/46 $\mathrm{mm} . \mathrm{Hg})$, feeding $(72 / 52 \mathrm{~mm} . \mathrm{Hg})$, and crying $(80 / 50$ $\mathrm{mm} . \mathrm{Hg}$ ). There was a fall in blood pressure with lowering the head $(55 / 40 \mathrm{~mm}$. $\mathrm{Hg})$. The mean blood pressure when flat was $49 \mathrm{~mm}$. $\mathrm{Hg}$. The two infants with convulsions due to perinatal anoxia behaved similarly.

Blood pressure recordings during exchange transfusion (Fig. 8) showed that the blood pressure dropped when the blood was withdrawn and it rose when blood was injected. The average rise or fall in systolic blood pressure on injecting or withdrawing $20 \mathrm{ml}$. of blood was $8 \mathrm{~mm}$. $\mathrm{Hg}$, but on many occasions much higher rises or falls (up to $15 \mathrm{~mm}$. $\mathrm{Hg}$ ) were noted. Changes in diastolic blood pressure were of a lesser magnitude, the average being $6 \mathrm{~mm}$. $\mathrm{Hg}$, though at times there was a rise or fall of $10 \mathrm{~mm}$. Hg. It was noted also that this change in blood pressure was less often seen towards the end of an exchange transfusion suggesting that the circulation was becoming adjusted to the rapid changes in blood volume (Fig. 8).

Infants of Birth Weight 1,501-2,500 g. The 'normal' babies in this group had similar blood pressure readings to the infants of diabetic mothers weighing more than $2,500 \mathrm{~g}$. Thus their blood pressure when flat was $70 / 46$ with a mean blood pressure of $60 \mathrm{~mm}$. $\mathrm{Hg}$. This rose to $75 / 57 \mathrm{~mm}$. Hg when sitting up, $86 / 46 \mathrm{~mm}$. $\mathrm{Hg}$ when feeding, and $93 / 51 \mathrm{~mm}$. $\mathrm{Hg}$ when crying. It fell to $65 / 44 \mathrm{~mm}$. $\mathrm{Hg}$ when the head was lowered. There was no significant change in the blood pressure of one infant during a tube feed. Babies with respiratory distress syndrome also showed no significant change from those babies with the respiratory distress syndrome
TABLE 1

CLINICAL CONDITION OF BABIES WHOSE UMBILICAL ARTERIAL BLOOD PRESSURE WAS RECORDED

\begin{tabular}{|c|c|c|c|c|}
\hline \multicolumn{4}{|l|}{ Patient } & Number \\
\hline \multicolumn{3}{|c|}{$\begin{array}{l}\text { Birth weight more than } 2,500 \mathrm{~g} \text {. } \\
\text { Infants of diabetic mothers } \\
\text { Infants with respiratory distress syndrome (RDS) } \\
\text { Infants with fits due to perinatal anoxia } \\
\text { Infants with haemolytic disease of the newborn }\end{array}$} & $\begin{array}{l}\cdots \\
\cdots \\
\cdots\end{array}$ & $\begin{array}{l}6 \\
3 \\
2 \\
4\end{array}$ \\
\hline $\begin{array}{l}\text { Birth weight } 1,501-2,500 \mathrm{~g} . \\
\text { Small for gestation: }\end{array}$ & $\begin{array}{l}\text { 'Normal'* } \\
\text { RDS } \\
\text { RDS } \quad \ldots\end{array}$ & $\begin{array}{l}\cdots \\
\cdots \\
\cdots\end{array}$ & $\begin{array}{l}\cdots \\
\cdots \\
\cdots\end{array}$ & $\begin{array}{l}5 \\
5 \\
6\end{array}$ \\
\hline \multirow[t]{2}{*}{$\begin{array}{l}\text { Birth weight less than } 1,500 \mathrm{~g} \text {. } \\
\text { Small for gestation: } \\
\text { Normal weight for gestation: }\end{array}$} & $\begin{array}{l}\text { 'Normal'* } \\
\text { RDS } \quad \cdots \\
\text { RDS } \quad \cdots \\
\text { Cardiac arrest } \\
\text { IVH } \quad \cdots\end{array}$ & $\begin{array}{l}\cdots \\
\cdots \\
\cdots \\
\cdots\end{array}$ & \begin{tabular}{l|}
$\cdots$ \\
$\cdots$ \\
$\cdots$ \\
$\cdots$
\end{tabular} & $\begin{array}{l}2 \\
2 \\
6 \\
1 \\
1\end{array}$ \\
\hline & Total & . & $\ldots$ & 43 \\
\hline
\end{tabular}

* See text.

RDS $=$ respiratory distress syndrome.

IVH = intraventricular haemorrhage.

weighing more than $2,500 \mathrm{~g}$. (see Table 2). There was no difference in blood pressure between infants of normal weight for their gestation and those that were small for their gestation.

Infants of Birth Weight Less than 1,500 g. In contrast to infants weighing more than $1,500 \mathrm{~g}$., these infants had a low blood pressure with an average of $66 / 43 \mathrm{~mm}$. Hg when flat and a mean of $54 \mathrm{~mm}$. Hg. They also showed a rise in blood pressure with crying and on sitting up. The blood pressure fell when the head was held low. Babies with the respiratory distress syndrome in this group similarly had low blood pressures compared with those weighing more than $1,500 \mathrm{~g}$. with the respiratory distress syndrome. On tube feeding there was no change in the blood pressure except during the process of passing the tube if the baby struggled.

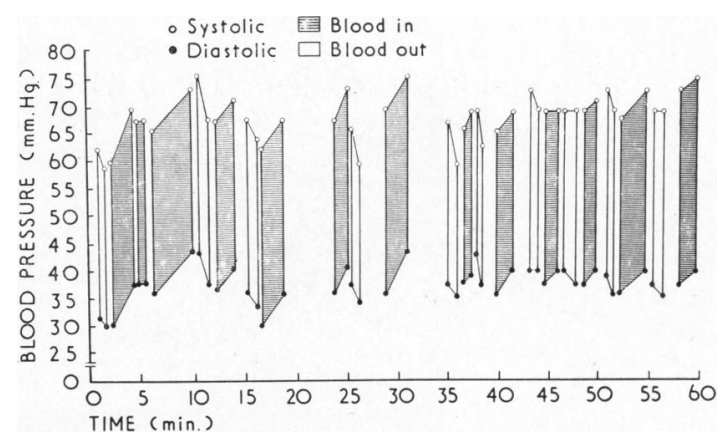

FIG. 8.-Direct blood pressure recording from umbilical artery during an exchange transfusion in a baby of $2,780 \mathrm{~g}$. Open circles-systolic pressure. Closed circles-diastolic pressure. Shaded areas-during injection of $20 \mathrm{ml}$. blood. Unshaded areas-during withdrawal of $20 \mathrm{ml}$. blood. 
TABLE 2

AVERAGES OF DIRECT ARTERIAL BLOOD PRESSURE MEASUREMENTS FROM UMBILICAL ARTERY

\begin{tabular}{|c|c|c|c|c|c|c|c|}
\hline \multirow{2}{*}{ Type of Patient } & \multicolumn{7}{|c|}{ Blood Pressures (mm. Hg) } \\
\hline & Flat & Head up & Head down & Mean & Feed & Tube-feed & Crying \\
\hline $\begin{array}{l}\text { Birth weight more than } 2,500 \mathrm{~g} . \\
\text { Infants of diabetic mothers } \\
\text { RDS } \\
\text { Fits due to perinatal anoxia }\end{array}$ & $\begin{array}{l}71 / 48 \\
63 / 45 \\
62 / 39\end{array}$ & $\begin{array}{l}80 / 57 \\
68 / 46 \\
63 / 43\end{array}$ & $\begin{array}{l}65 / 44 \\
55 / 40 \\
58 / 35\end{array}$ & $\begin{array}{l}58 \\
49 \\
51\end{array}$ & $\begin{array}{c}78 / 56 \\
72 / 52 \\
-\end{array}$ & - & $\begin{array}{l}92 / 53 \\
80 / 50 \\
\end{array}$ \\
\hline 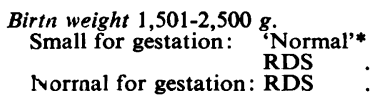 & $\begin{array}{r}70 / 46 \\
61 / 36 \\
62 / 39\end{array}$ & $\begin{array}{l}75 / 57 \\
64 / 38 \\
67 / 47\end{array}$ & $\begin{array}{l}65 / 44 \\
54 / 30 \\
60 / 35\end{array}$ & $\begin{array}{l}60 \\
46 \\
46\end{array}$ & $\begin{array}{c}86 / 46 \\
75 / 55 \\
-\end{array}$ & 二 & $\begin{array}{l}93 / 51 \\
67 / 32 \\
64 / 46\end{array}$ \\
\hline $\begin{array}{l}\text { Birth weight less than } 1,500 \mathrm{~g} . \\
\text { Small for gestation: 'Normal'* } \\
\text { Normal for gestation: RDS } \\
\text { Norm }\end{array}$ & $\begin{array}{l}66 / 43 \\
51 / 33 \\
50 / 30\end{array}$ & $\begin{array}{l}73 / 49 \\
58 / 46 \\
58 / 38\end{array}$ & $\frac{66 / 43}{40 / 20}$ & $\begin{array}{l}54 \\
41 \\
39\end{array}$ & 二 & $\overline{48 / 34}$ & $\begin{array}{c}75 / 50 \\
66 / 39 \\
-\end{array}$ \\
\hline
\end{tabular}

- See text.

There was no change in blood pressure with the different periods of respiration in one infant with periodic breathing.

Fig. 9 shows the effect of external cardiac massage in an infant who had cardiac arrest following an apnoeic attack. The external cardiac massage always produced a large pulse wave. Following the cardiac massage the heart began to beat spontaneously and the blood pressure, which was unrecordable previously, rose to $44 / 32 \mathrm{~mm}$. $\mathrm{Hg}$.

\section{Discussion}

A striking feature of the blood pressure of newborn babies is its variability (Figs. 2, 6, and 7), a fact that impinges on its use as a clinical measurement of any value. For instance, like Moss, Duffie, and Emmanouilides (1963) but unlike Young and Holland (1958), we found that crying, even in the first day of life, produced a large rise in both systolic and diastolic pressures (Table 2). Apart from the inaccuracies inherent in inadequate attention to technical details such as cuff size and pulse detection, a single estimation of blood pressure is clearly inadequate unless proper attention is given to ensuring that the child is quiet and comfortable during the examination. A continuous recorder has the advantage that a basal level is clearly seen after an hour or two of recording, a procedure that would be too time consuming for ordinary clinical use.

The rise in blood pressure during feeding is
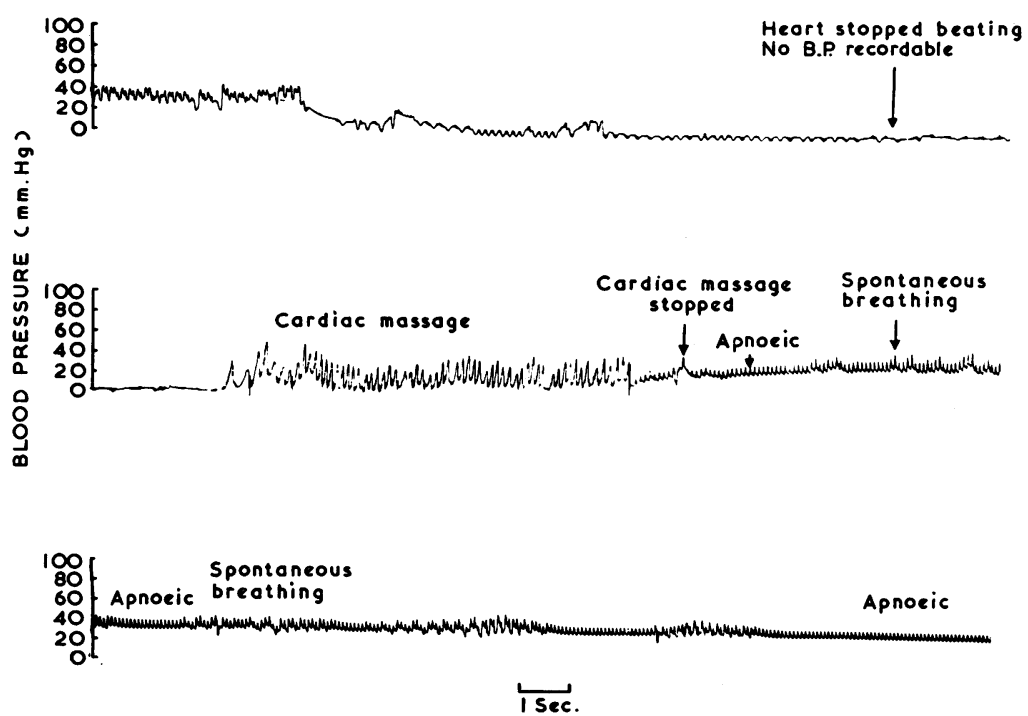

FIG. 9.-Direct blood pressure recording from umbilical artery in a baby during an episode of cardiac arrest. The three lines of tracing are in chronological order but the time scale is not continuous. 
particularly obvious. It is a fairly common practice to measure a baby's blood pressure during a feed, because then the child is comparatively quiet. It is clear from our data that such a practice will not give a 'basal' blood pressure. It certainly appears that sucking, tilting, and 'arousal' contribute to this rise in blood pressure.

Tilting up a baby increases noradrenaline output (Greenberg, Lind, and von Euler, 1960) and sucking may also do so. Hakulinen, Hirvonen, and Peltonen (1962) found a rise in blood pressure during sucking and attributed it to the physical work involved, but it might equally well be a consequence of emotional excitement engendered by feeding. The rise in blood pressure provides one very good reason for feeding babies in cardiac difficulty by gavage.

The absence of a circadian rhythm is an interesting finding. Most normal babies are showing a circadian rhythm in wakefulness, pulse rate, and body temperature by about 3-6 weeks (Hellbrugge, 1960). We did not examine normal babies of 1 month, and the absence of circadian rhythm in premature babies of 6 weeks could be due to their prematurity (Hellbrugge, 1960) or to the abnormal environment of a premature unit where attendants, artificial light, and feeds are available throughout the night.

The rhythmic changes observed were related to the artificial rhythm of feeds and the natural rhythm of sleep (Goldie, 1964). The rhythm can be disturbed by external stimuli, and in our experience babies in hospital, especially premature babies, seldom have many consecutive hours without interference such as physical examination, blood tests, weighing, nappy change, and other nursing procedures.

The absolute levels recorded by direct measurements are in general agreement with the findings of other workers (Rudolph, Drorbaugh, Auld, Rudolph, Nadas, Smith, and Hubbell, 1961 ; Moss et al., 1963). There are, however, one or two interesting features. The blood pressures of babies between 1,500 and $2,500 \mathrm{~g}$. are not materially different from those of bigger babies. In babies below $1,500 \mathrm{~g}$. the blood pressure is, however, lower (Table 2), as it is in babies suffering from respiratory distress syndrome. The blood pressure of babies who are 'small for dates' is more clearly related to the weight of the baby rather than to its gestational age. In animals, the blood pressure at birth is related to length of gestation (Dawes, 1961) but there is no information about the 'small for dates' animal (runts) in his figures.

There are conflicting reports regarding the effect of posture on blood pressure. Young and Holland (1958), measuring blood pressure indirectly by palpation, reported that there was no change on tilting the baby in the first three days of life, but a rise in systolic pressure which was maintained for at least two minutes on tilting to the head-up position occurred after the third day. Moss et al. (1963), measuring blood pressure directly via the umbilical artery, showed a small immediate increase on tilting to a head-up position followed by a short drop in both systolic and diastolic pressures with a subsequent rapid (within 20 seconds) return to the pre-tilt level, and this occurred even in the first day of life. Our own observations showed that there was a rise in both systolic and diastolic pressures on tilting to the head-up position, which was maintained for at least two minutes. This occurred even during the first day of life and also in premature, sometimes ill, babies. Unlike Young, we also found a fall in blood pressure on tilting to the head down position.

External cardiac massage is of undoubted value in resuscitating asphyxiated newborn animals (Adamsons, Behrman, Dawes, James, and Koford, 1964) and babies (personal observation and Fig. 9). In one patient in whom blood pressure was being recorded, there was cardiac standstill. External cardiac massage produced a good pulse pressure and the heart began to beat spontaneously again (Fig. 9). This was followed by spontaneous respiration which can be seen on the tracing by the respiratory fluctuations in blood pressure. The magnitude of the pulse wave and the efficiency of the treatment are demonstrated by this tracing.

Babies with the respiratory distress syndrome were consistently found to have low blood pressures (systolic and diastolic) compared with 'normal' term and premature babies of similar birth weight. The

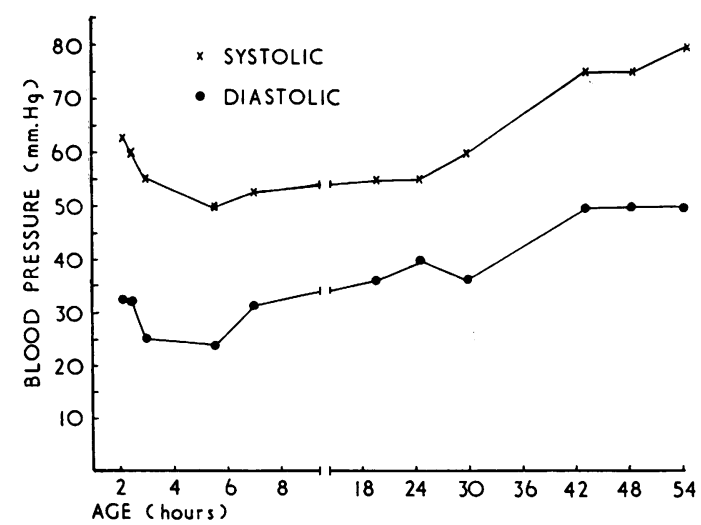

Fig. 10.-Direct blood pressure recording from the umbilical artery in a baby of $2,100 \mathrm{~g}$. who developed and recovered from respiratory distress syndrome. All points plotted refer to records taken when the child was quiet. Note the discontinuous time scale. 
fall in blood pressure coincided with the deterioration in the child's condition in the first hours of life. Subsequently, a steady rise occurred as the condition ameliorated (Fig. 10). A low systemic pressure in the presence of an open ductus arteriosus may well account for part of the right-to-left shunt known to occur in infants with severe respiratory distress (Strang and MacLeish, 1961; Warley and Gairdner, 1962). The low blood pressure in babies with respiratory distress has been reported by other authors (Neligan and Smith, 1960; Rudolph et al., 1961).

Exchange transfusion produces large rapid fluctuations in blood pressure, though it is our practice to perform each individual manoeuvre slowly (e.g. two minutes to inject $20 \mathrm{ml}$. blood). The blood pressure, however, rapidly returned to 'basal' level if one stopped for a minute or two, and it was a common finding that towards the end of the procedure the fluctuations were less wide. This again suggests that vasomotor control at this age is far from inadequate.

\section{Summary}

An apparatus which automatically records blood pressure at 2-minute intervals in babies is described. The fluctuations and rhythms in a baby's blood pressure are demonstrated. Although there is no circadian rhythm in babies, there is a rhythm related to feeds. Feeding itself causes a large rise in blood pressure and the reasons for this rise are analysed. Direct arterial blood pressure readings from a number of babies are reported and analysed according to weight, gestation, and clinical condition. In 'small for dates' babies, the blood pressure is more closely related to the size of the baby than to his gestational age. The efficiency of external cardiac massage in producing a pulse pressure is demonstrated. The general contention that vasomotor regulatory mechanisms are functioning in babies is supported.
We are grateful to the trustees of the Sir William Coxen fund for equipment and laboratory facilities, and to the Nuffield Foundation and the Clothworkers Company for grants, which made this work possible. We also wish to thank Mr. J. E. Pallett, Dr. Gordon Ball, and Mr. K. T. Lanning for their invaluable help in the design and construction of the automatic recorder.

\section{REFERENCES}

Adamsons, K., Jr., Behrman, R., Dawes, G. S., James, L. S., and Koford, C. (1964). Resuscitation by positive pressure ventilation and trishydroxymethylaminomethane of rhesus monkeys asphyxiated at birth. J. Pediat., 65, 807.

Ashworth, A. M., Neligan, G. A., and Rogers, J. E. (1959). Sphygmomanometer for the newborn. Lancet, 1, 801.

Ball, G. R., Pallett, J., and Shillingford, J. P. (1961). An automatic finger blood-pressure recorder. ibid., $2,1178$.

Dawes, G. S. (1961). Changes in the circulation at birth. Brit. med. Bull., 17, 148.

de Bono, E. F. (1963). A simple method of intra-arterial pressure measurement. Lancet, 1, 1142.

Goldie, L. (1964). Innate sleep rhythms in newborn infants. Paper read at The Paediatric Research Society Meeting 20.3.64.

Greenberg, R. E., Lind, J., and von Euler, U. S. (1960). Effect of posture and insulin hypoglycemia on catecholamine excretion in the newborn. Acta paediat. (Uppsala), 49, 780.

Hakulinen, A., Hirvonen, L., and Peltonen, T. (1962). Response of blood presure to sucking and tilting in the newborn infant. Ann. Paediat. Fenn., 8, 56.

Hellbrugge, T. (1960). The developmert of circadian rhythms in infants. Cold Spr. Harb. Symp. quant. Biol., 25, 311.

Moss, A. J., Duffie, E. R., Jr., and Emmanouilides, G. (1963). Blood pressure and vasomotor reflexes in the newborn infant. Pediatrics, 32, 175.

Neligan, G. A., and Smith, C. A. (1960). The blood pressure of newborn infants in asphyxial states and in hyaline membrane disease. ibid., 26, 735 .

Pallett, J. E. (1962). A new transducer for recording finger pulsation. J. sci. Instrum., 39, 489.

Rudolph, A. M., Drorbaugh, J. E., Auld, P. A. M., Rudolph, A. J., Nadas, A. S., Smith, C. A., and Hubbell, J. P. (1961). Studies on the circulation in the neonatal period-the circulation in the respiratory distress syndrome. Pediatrics, 27, 551 .

Strang, L. B., and MacLeish, M. H. (1961). Ventilatory failure and right-to-left shunt in newborn infants with respiratory distress. ibid., 28, 17.

Warley, M. A., and Gairdner, D. (1962). Respiratory distress syndrome of the newborn-principles in treatment. Arch. Dis. Childh., 37, 455 .

Young, I. M., and Holland, W. W. (1958). Some physiological responses of neonatal arterial blood pressure and pulse rate. Brit. med. J., 2, 276.

Young, M. (1961). Blood pressure in the newborn baby. Brit. med. Bull., 17, 154. 